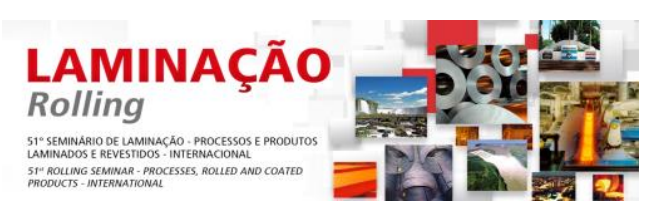

\title{
NOVEL LABORATORY LUBRICATION TESTS FOR COLD ROLLING EMULSIONS*
}

\author{
J. Bas A. F. Smeulders ${ }^{1}$
}

\begin{abstract}
Traditional laboratory lubrication tests, including those for cold rolling lubricants often involve measurement of neat oils. To achieve increased levels of test severity, such tests are often carried out at high temperatures and prolonged durations. However, we found that the levels of lubricant degradation and wear in these tests can be much higher than in the field. Moreover, steel rolling is not done with neat oils, but with emulsions, where the presence of water influences film formation, surface chemistry and oil composition in the roll bite. To better approach the situation in the field, and thus to be able to develop rolling oils with improved lubrication performance, several lubrication tests were developed for emulsions: direct measurement of film formation and measurement of Stribeck curves, in which the emulsions can be assessed in terms of their boundary lubrication and elastohydrodynamic behaviour. The key innovation is that also another test method was developed, which focuses on boundary lubrication and wear, and the role of extreme pressure and anti-wear additives. Realistic levels of test severity are achieved in the tribometer by mimicking frictional power intensities and flash temperatures for typical cold rolling or tinplate mills. Test conditions can be adapted according to the mill stand or pass number and other cold rolling process parameters. The emulsions are kept at normal operational temperature. Clear differences could be observed between emulsions of various concentration and composition. The viability of the method is illustrated by a number of field cases, in which a good correlation is demonstrated between the laboratory tests and the performance in a pilot or production mill.
\end{abstract}

Keywords: Physico-chemical properties; Film formation; Stribeck curves; Frictional power intensity; Flash temperature

1 Research Scientist, Quaker Chemical, Uithoorn, The Netherlands.

* Contribuição técnica ao $51^{\circ}$ Seminário de Laminação - Processos e Produtos Laminados e Revestidos, 28 a 31 de outubro de 2014, Foz do Iguaçu, PR, Brasil. 


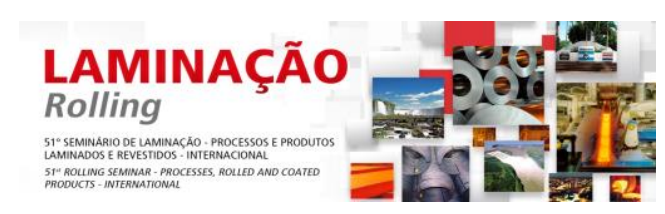

\section{INTRODUCTION}

Cold rolling involves intensive frictional contact between two highly loaded metallic surfaces in sliding contact. Together with the deformation-related parameters such as hardness and reduction, the frictional conditions in the roll bite determine the roll forces and torques required for rolling (see figure 1).

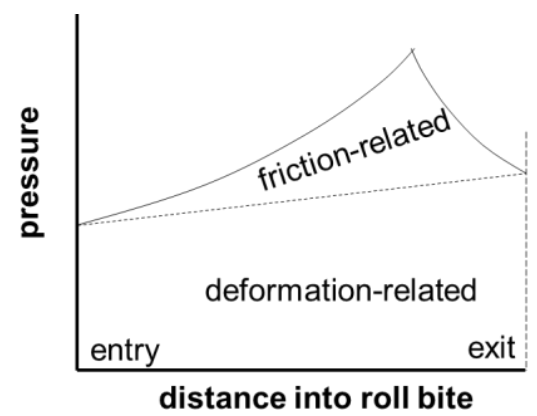

Figure 1. Schematic drawing of the pressure hill in the roll bite. The friction-related part can be influenced by the physico-chemical properties of the lubricant.

Steel manufacturers are often looking for ways to reduce these roll forces and torques, for instance allowing them to speed up the process. The alloy hardness and reductions are process requirements, and cannot be altered, but the friction in the roll bite can be influenced by considering the lubricant's physico-chemical properties. Just prior to the roll bite, we find the inlet, or entry zone, filled with lubricant. This zone is characterized by two fast-moving, converging surfaces. According to the Reynolds equation [1], under such conditions, pressures in the lubricant will rise, due to which a lubricant film will form between the mating surfaces. In cold rolling, due to the surface roughness, this film generally only partially separates the surfaces. So, just beyond the inlet zone, the surfaces will start to touch, and we can define the beginning of the roll bite, or contact zone, where the frictional conditions are determined. Cold rolling occurs in the so-called mixed lubrication regime. This means that in the roll bite there are both regions of some surface separation, where friction is determined by the rheological properties of the lubricant under high pressures, temperatures and shear rates, and regions of close surface contact, where friction is determined by the surface chemistry of strip and roll. The friction in the roll bite is strongly influenced by the properties of the lubricant, either through its bulk rheological properties, or by its ability to react with the mating surfaces. See figure 2 for a schematic drawing. In figure $2 a$ on the left we see the entry zone where the film thickness is determined, and in the middle the contact zone, where friction occurs due to the sliding of the work roll over the accelerating strip. In figure $2 b$ is illustrated that there are several lubrication regimes, such as the 'classic' boundary regime governed by adsorption (BLads), the EHL regime where the fluid traction determines the local friction, and a boundary region where potentially strong wear may occur, but which is addressed by the formation of a reaction layer $\left(B L_{e p / a w}\right)$. The MPHL regime represents the formation of a thin lubricant film due to in-bite film formation, as introduced earlier [2]. The role of the lubricant in each of these regimes is schematically illustrated in figure $2 \mathrm{c}$.

\footnotetext{
* Contribuição técnica ao $51^{\circ}$ Seminário de Laminação - Processos e Produtos Laminados e Revestidos, 28 a 31 de outubro de 2014, Foz do Iguaçu, PR, Brasil.
} 


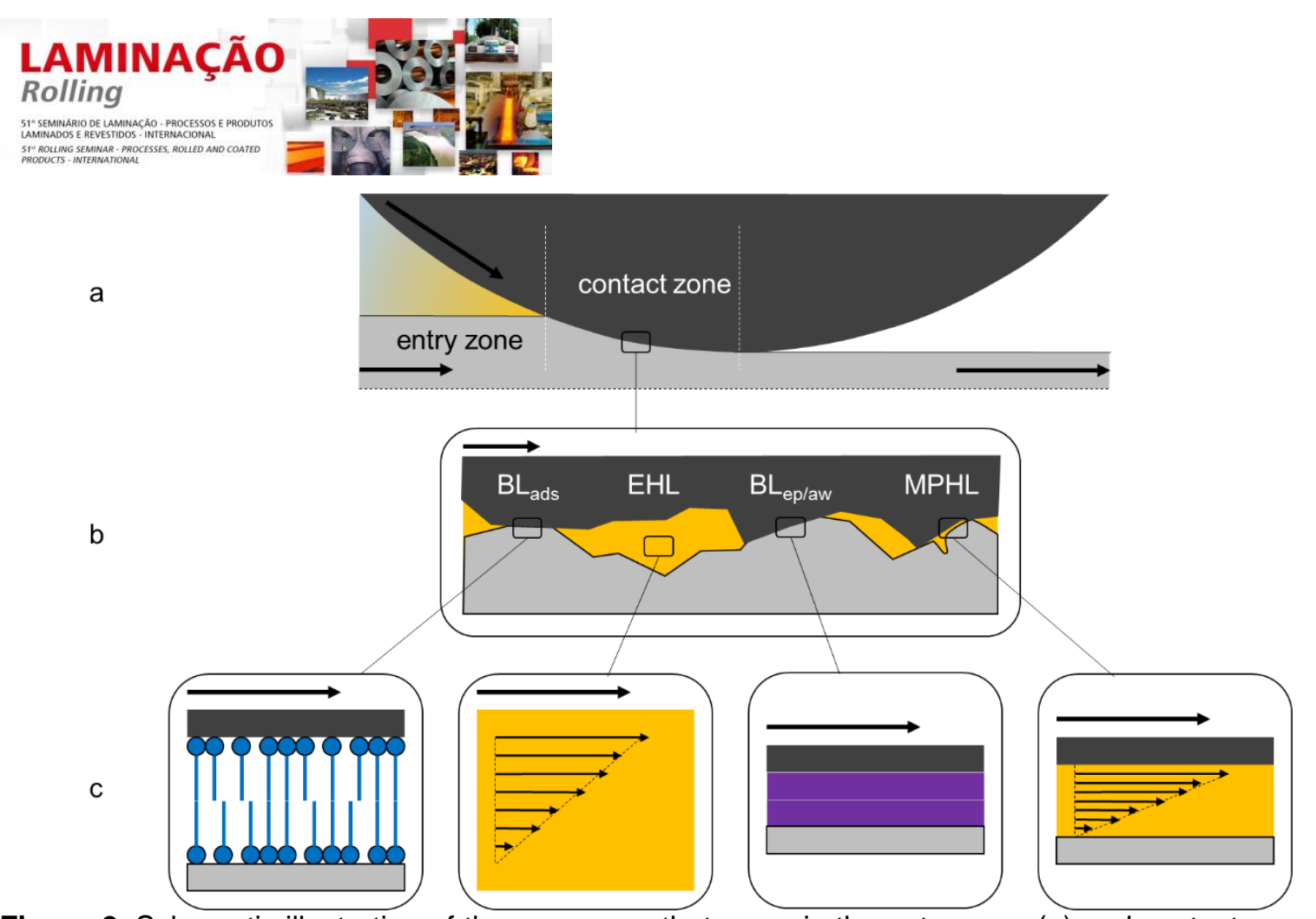

Figure 2. Schematic illustration of the processes that occur in the entry zone (a) and contact zone (b), all of which are governed by physico-chemical properties of the lubricant (c, schematically), which all potentially contribute to lubrication and hence the roll force/torques in cold rolling.

The physico-chemical properties of the lubricant important in rolling can be subdivided in the ones relevant in the entry zone, and the ones relevant in the contact zone.

As far as the entry zone is concerned we could mention 1) the oil droplet size, which in some theories plays an important role in trapping the oil droplet between the surfaces in order to drag it into the roll bite [3], 2) the oil droplet's surface tension, involved in the efficiency with which the oil film is built [4], 3) the lubricant's viscosity, which is a strong driving force for film formation, even when emulsions are used [5].

As far as the contact zone is concerned we can make a subdivision in bulk (rheological) properties and surface (chemical) properties. Important bulk rheological properties are1) viscosity, 2) viscosity-pressure index, such as the Barus $\alpha$-value [6] or the Roelands' z-value [7], 3) viscosity-temperature index, such as the VI or Roelands $S_{0}$ value $^{7}$, 4) numbers quantifying shear-thinning, such as the Eyring stress [8] $\tau_{0}$. Important properties related to surface chemistry are 1) the coefficient of friction in the boundary regime, influenced by molecular adsorption (physisorption or chemisorption) and 2) surface protection under severe conditions, influenced by the reaction of ep/aw additives with the mating surfaces. A 3-D Stribeck curve has proved useful to 'unite' some of the parameters described above [2,9].

For a rolling oil manufacturer is important to be able to test a lubricant in view of its cold rolling performance. This will be the subject of the main part of this paper, but first we need to look at two fundamental choices we have to make in view of tribological testing: in view of test severity and in view of using emulsions.

Often (boundary) lubrication tests are carried out at high temperatures and for prolonged durations. This makes sense if such conditions also (potentially) occur in the envisaged application, such as engines or bearings. However, in cold rolling the lubricant is not exposed to high temperatures for prolonged durations. It can be calculated (on the basis of an estimated oil flux through all of the bites and the total oil in the system) that for a typical tandem mill, on average, every oil particle is exposed to in-bite conditions roughly once per day. Assuming an average residence

* Contribuição técnica ao $51^{\circ}$ Seminário de Laminação - Processos e Produtos Laminados e Revestidos, 28 a 31 de outubro de 2014, Foz do lguaçu, PR, Brasil. 


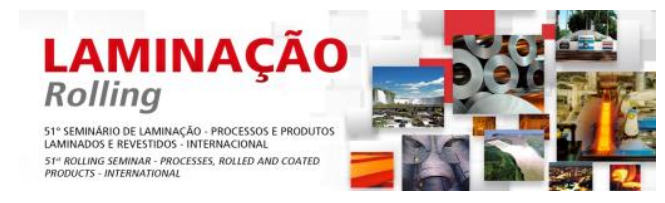

time of $1 \mathrm{~ms}$, and a refreshment rate of the oil of once per 15 days, the total exposure of the oil to the frictional conditions in the bite is of order 0.015 seconds. This is of course, vastly different to the exposure of the oil to high temperatures in some laboratory tests. This calculation shows us that long-term, high-temperature lubrication tests for cold rolling lubricants are not recommended.

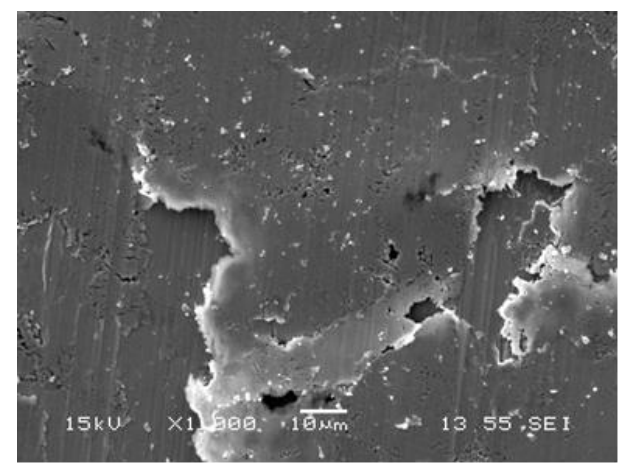

Figure 3. Fatigue wear in an oscillatory tribometer.

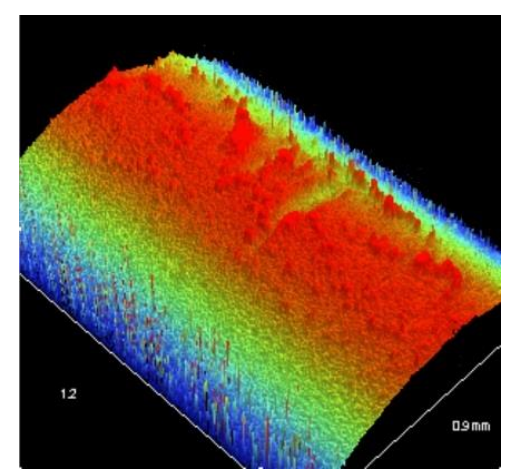

Figure 4. Tribometer tool with adhesion

We can also look at the wear processes that sometimes occur in (long-duration) laboratory tests. Due to the oscillatory nature of many tests, and to the resulting periodic stresses on, especially, the softer of the mating surfaces, fatigue wear can occur, which is unlikely to happen on the strip surface during the passage in the 5 stands in the mill. An example is shown in figure 3. Furthermore, in some longduration tests, adhesion processes can occur. This involves the transfer (or welding) of the softer material onto the harder tool. This roughens this surface significantly, and will influence the rest of the test, i.e. it is an undesirable history effect. An example of a cylinder, having been loaded and oscillated on a soft steel panel, and which is damaged by adhesion is shown in figure 4 .

Some of the more traditional lubrication tests for cold rolling lubricants use the neat oil as test fluid, even though emulsions are used in the field. Furthermore, lubrication provided by emulsions may differ from that of neat oils, on 3 accounts.

1. Film formation from emulsions is different from that of neat oils. The film formation of neat oils is determined by viscosity and $\alpha$-value, but the film formation of emulsions is (additionally) determined by the efficiency with which an oil film is formed out of the emulsion, through various (hypothesized) mechanisms presented in literature ${ }^{9}$. This is schematically illustrated in figure 5 , where due to starvation, the film thickness with emulsions is lower than that for neat oils.

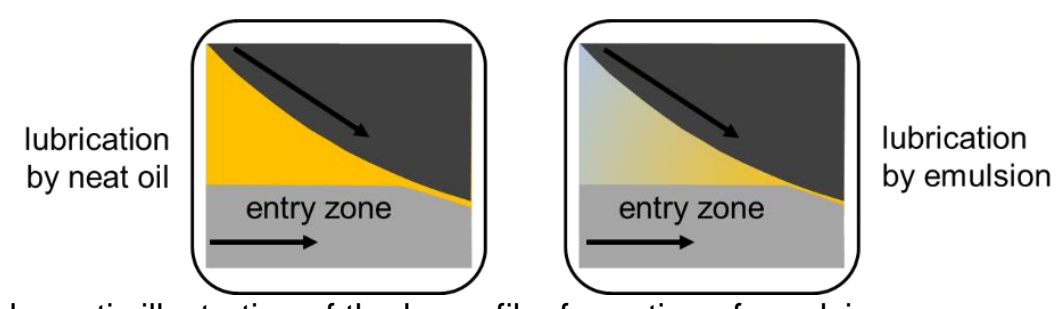

Figure 5. Schematic illustration of the lower film formation of emulsions compared to neat oils.

\footnotetext{
* Contribuição técnica ao $51^{\circ}$ Seminário de Laminação - Processos e Produtos Laminados e Revestidos, 28 a 31 de outubro de 2014, Foz do Iguaçu, PR, Brasil.
} 


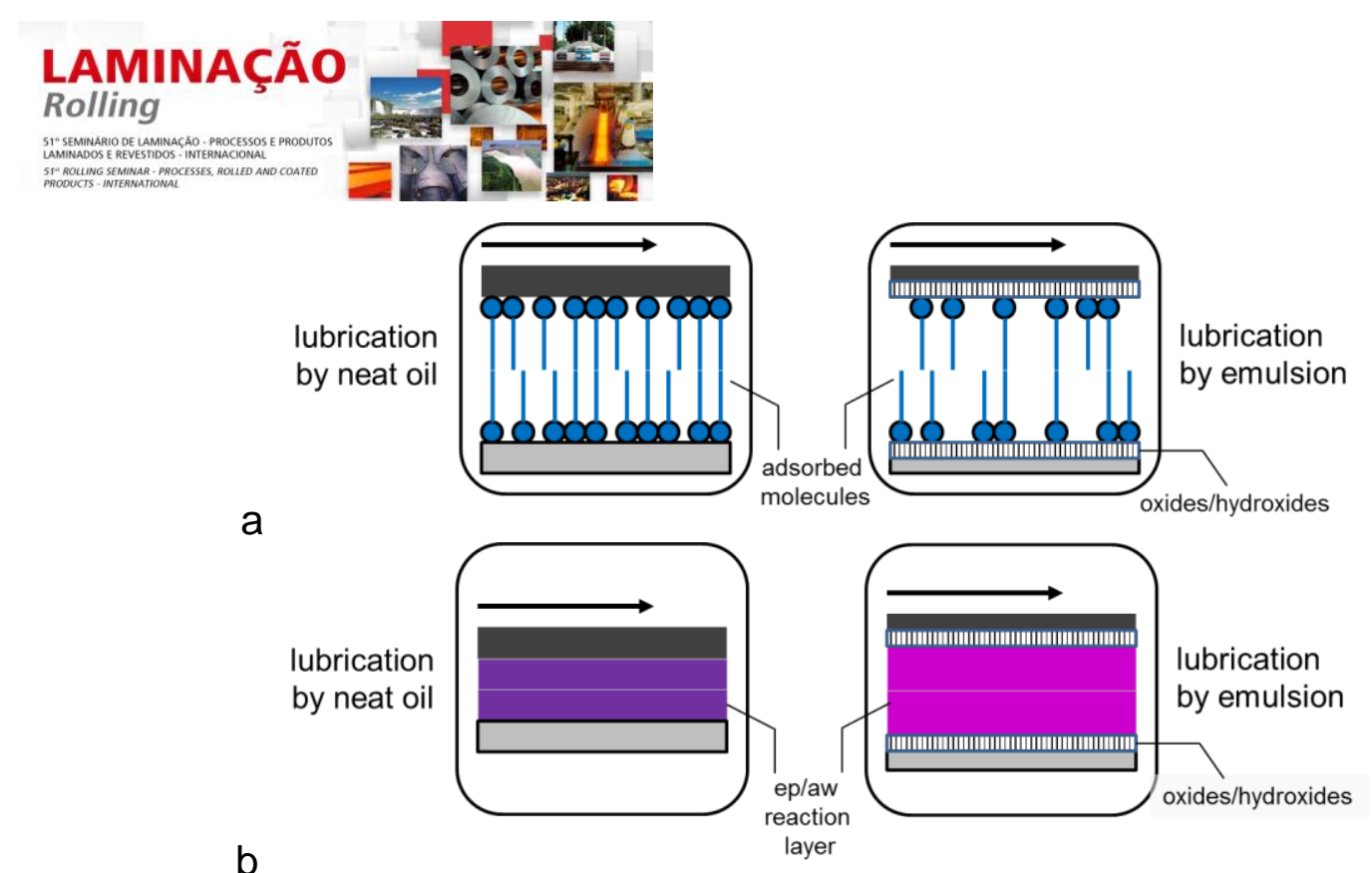

Figure 6. Schematic illustrations of the effect water may have on the chemical nature of the mating surfaces, e.g. by the presence of oxides or hydroxides, and the effect this may have on friction-reducing adsorption processes (a) and the reaction of ep/aw additives (b).

2. The boundary lubrication of emulsions is different from neat oils. This is because the surface reactions involved in boundary lubrication rely strongly on the chemical state of the metallic surfaces, e.g. due to the presence of (different amounts/types of) oxides or hydroxides, which in turn is influenced by the presence of water. In figure 6 this is illustrated by the effect on adsorption (a) and thickness/type of ep/aw reaction layer (b). Note that this illustration is schematic and increased adsorption or thinner ep/aw reaction layers are also possible. Note also that the surfaces in a neat oil environment are not necessarily free of oxides/hydroxides.

3. The chemical composition of the oil in the roll bite, which provides the lubrication in the bite is not the same as that of the original oil in the storage tank (as delivered by the oil supplier) as illustrated in figure 7. This is due to the dissolution in the water phase of the water-soluble components of the original formulation, and thus their removal from the oil phase. Because it has been experimentally demonstrated that boundary lubrication may be (strongly) influenced by the presence or absence of any surface active or reactive chemical component, using the original neat oil in lubrication tests may no longer be representative of the performance of the oil in the roll bite.

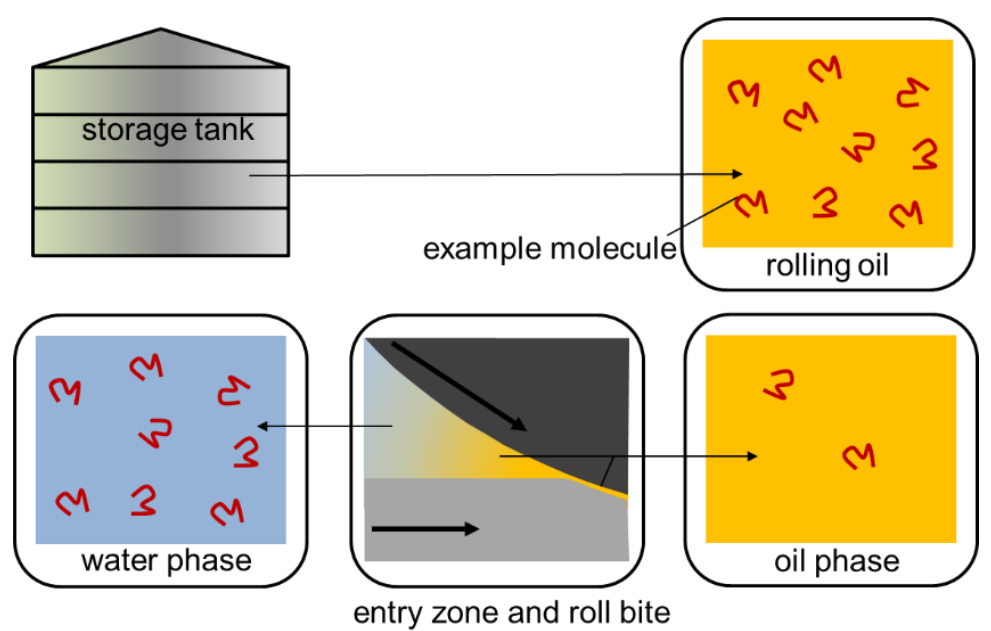

Figure 7. Schematic illustration of the fact that the composition of the oil in the roll bite is different from the rolling oil supplied to the steel manufacturer.

* Contribuição técnica ao $51^{\circ}$ Seminário de Laminação - Processos e Produtos Laminados e Revestidos, 28 a 31 de outubro de 2014, Foz do Iguaçu, PR, Brasil. 


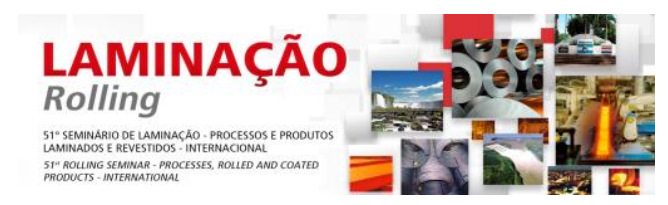

\section{RESULTS AND DISCUSSION}

Because of the arguments sketched above, laboratory lubrication tests are preferably carried out using emulsions. Film formation as well as entire Stribeck curves can be tested using emulsions.

Figure 8 shows the film thickness from two emulsions (two emulsifier packages $A$ and $B$ in the same base oil), measured with an ultra-thin film interferometer, introduced before [2]. The film thickness of emulsions is initially equal to the corresponding neat oil (dotted line), but starts to deviate at a certain entrainment speed, due to starvation [9]. At this point the emulsion can no longer supply the oil to the contact as required by speed and viscosity, the oil pool immediately in front of the roll bite vanishes, and the film thickness starts to deviate. This behavior depends significantly on the chosen emulsifier package, as illustrated in figure 8.

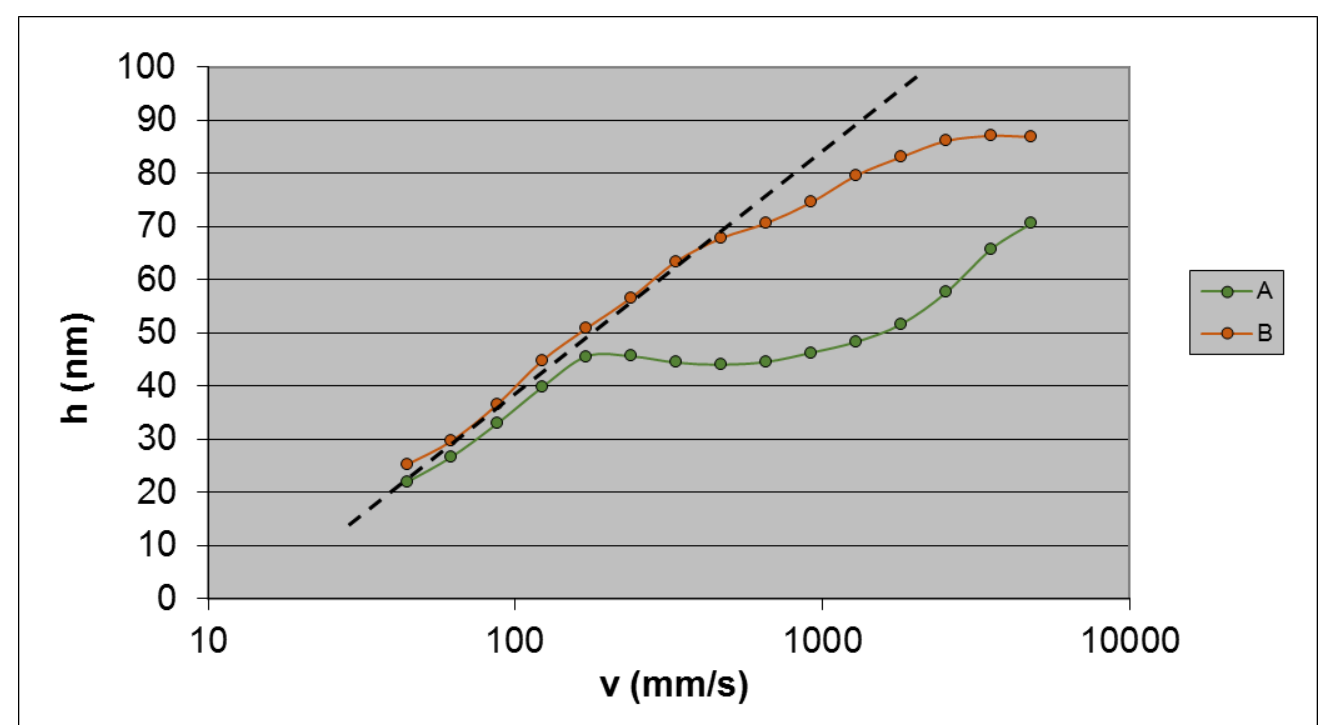

Figure 8. Film thickness measurement. The emulsions $A$ and $B$, with different emulsifiers, initially show the neat oil behavior (dotted line), but deviate at higher speeds.

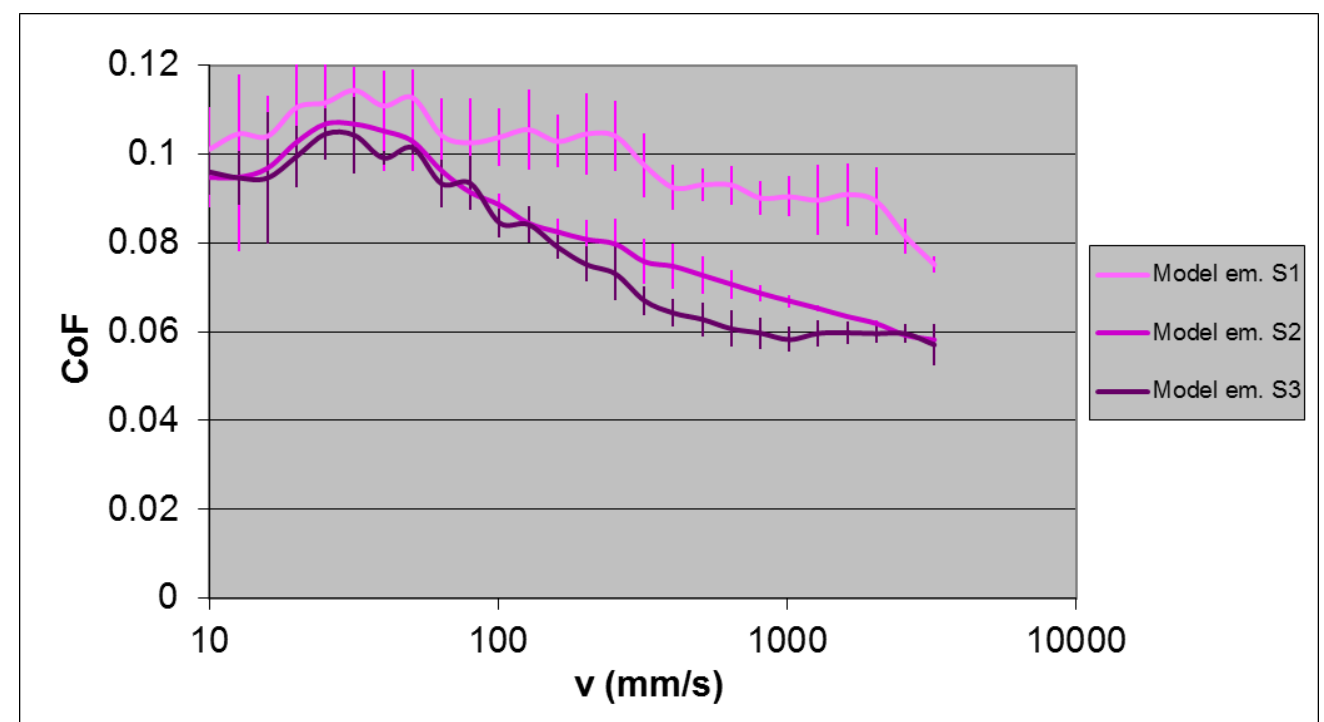

Figure 9. Stribeck curves. The CoF values decrease going from S1 to S2 and S3. The performance in a pilot mill improves in the same order.

* Contribuição técnica ao $51^{\circ}$ Seminário de Laminação - Processos e Produtos Laminados e Revestidos, 28 a 31 de outubro de 2014, Foz do Iguaçu, PR, Brasil. 


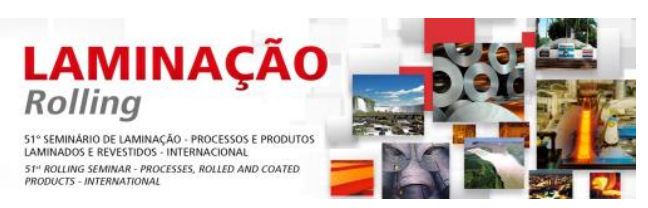

In figure 9 we can see the Stribeck curves of three model emulsions. At low speeds we see the boundary lubrication regime, representative of adsorption processes on the mating surfaces. The coefficient of friction in this regime may depend on the emulsion composition. As speeds increase, the separation between the mating surfaces generally increases and we enter the mixed lubrication regime (ML). Depending on the film formation properties of the emulsion, the transition from BL to ML may occur at different speeds for different emulsions. At the highest speeds, further differences between emulsions may be found. This may have two reasons. Firstly, it can be due to film formation. With an emulsion that supplies sufficiently thick films to the contact the EHL regime may be approached, whereas with an emulsion that supplies thinner films to the contact ML conditions will be maintained. Secondly it may be due to the value of the CoF in the EHL regime, mainly influenced by the lubricant's viscosity at high pressures, as explained earlier ${ }^{2,9}$. In figure 9 we see clear differences between the 3 emulsions. On a pilot mill (not gauge controlled, i.e. constant roll force) the achieved reductions at a rolling speed of $300 \mathrm{~m} / \mathrm{min}$ were $25 \%$, $31 \%$ and $34 \%$, for emulsions S1, S2 and S3, respectively.

\subsection{Novel test Methods for Cold Rolling Emulsions}

In cold rolling it is also important to provide protection to the strip and roll surface, in order to prevent local metallic contact and intra-metal shear. This is traditionally done by incorporating reactive sulfur and phosphorus compounds. The reaction of such compounds is generally triggered by the high temperatures occurring (locally) in the roll bite. However, when using emulsions in a tribometer, temperatures above $100^{\circ} \mathrm{C}$ cannot be chosen because of the evaporation of water and also because of the fact that the emulsion's (film formation) properties are no longer representative at excessive temperatures. Emulsions are thus preferably used at their operational temperatures, e.g. $50^{\circ} \mathrm{C}$.

Yet, we want to achieve sufficiently severe conditions in the contact of the tribometer, conditions such that surface protection is required, and ep/aw additives will react with the surfaces. This is done in two ways, firstly by mimicking the frictional energies encountered in rolling, and secondly by mimicking the flash temperatures encountered in rolling.

In any frictional process we can define the frictional power intensity [10] (FPI), which is the frictional power (FP) divided by the contact surface area $A$, as shown in equation 1. Its units are $\mathrm{W} / \mathrm{m}^{2}$.

$$
F P I=\frac{F P}{A}=\frac{0.5 \mu F_{N} \Delta v}{A}
$$

In this equation $\mu$ is the coefficient of friction, $F_{N}$ the load, and $\Delta v$ the sliding velocity. The factor 0.5 is due to the fact that the power is divided over two surfaces. In frictional processes we can also define the energy pulse ${ }^{10}$ (EP), which is the total amount of frictional energy a tribo-surface receives per unit area, i.e. it is the FPI multiplied by the time of duration $\mathrm{tc}_{\mathrm{c}}$, as shown in equation 2. Its units are $\mathrm{J} / \mathrm{m}^{2}$.

$$
E P=F P I \cdot t_{c}
$$

For each stand in a rolling mill, the FPI and EP can be estimated. In equation 1, in order to calculate the frictional power intensity, we need to account for the average

\footnotetext{
* Contribuição técnica ao $51^{\circ}$ Seminário de Laminação - Processos e Produtos Laminados e Revestidos, 28 a 31 de outubro de 2014, Foz do Iguaçu, PR, Brasil.
} 


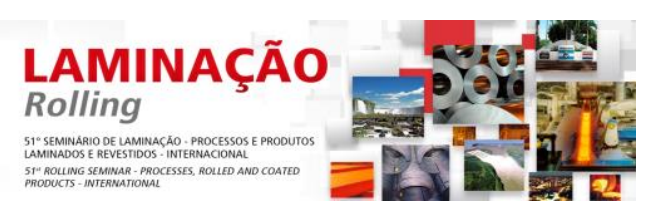

coefficient of friction, the load (i.e. roll force), the average sliding speed (which is a function of reduction and process speed) and the contact area, which is the product of strip width and contact length. In equation 2, in order to estimate the energy pulse of the strip, we additionally need to account for the time of contact, which equals the contact length divided by the average strip speed.

The surfaces involved in tribo-contact will receive momentary temperature increases due to the frictional conditions. These are called flash temperatures and can be calculated with the equation proposed by Blok [11], equation 3.

$$
\Delta T_{f}=1.11 \frac{\mu F_{N} \Delta v}{b\left(\sqrt{v_{1}}+\sqrt{\left.v_{2}\right)}\right.} \frac{1}{W \sqrt{L_{c}}}
$$

In this equation, $\mu$ is the average coefficient of friction in the contact, $F_{N}$ the load, $\Delta v$ the average sliding speed, $v_{1}$ and $v_{2}$ the absolute (average) speeds of the two mating surfaces, $W$ the strip width and $L_{c}$ the contact length. The value of $b$ ('thermal contact coefficient') is a function of thermal diffusivity $k$, density $\rho$ and specific heat $C_{p}$ (for steel $\left.k=55 \mathrm{~W} / \mathrm{mK}, \rho=7800 \mathrm{~kg} / \mathrm{m}^{3}, C_{p}=460 \mathrm{~J} / \mathrm{kgK}, b=\sqrt{ }\left(k \rho C_{p}\right)=1.41 \cdot 10^{4}\right)$. The equation by Blok is equally valid in a tribometer as it is in cold rolling, so the required conditions in the tribometer can be calculated to mimic the flash temperatures in cold rolling.

Table 1. The chosen mill conditions for the calculations, and the values of the frictional power intensity, energy pulse and flash temperatures

\begin{tabular}{|l|c|c|c|}
\hline & stand 2 sheet & stand 4 sheet & stand 5 tinplate \\
\hline$h_{0}(\mathrm{~mm})$ & 1.9 & 0.9 & 0.23 \\
\hline $\mathrm{r}(\%)$ & 30 & 40 & 30 \\
\hline $\mathrm{V}_{\mathrm{s}}(\mathrm{m} / \mathrm{s})$ & 5 & 11 & 28 \\
\hline $\mathrm{F}_{\mathrm{N}}(\mathrm{specific})($ ton $/ \mathrm{m})$ & 900 & 1150 & 1100 \\
\hline$\mu(-)$ & 0.08 & 0.04 & 0.035 \\
\hline $\mathrm{FPI}\left(\mathrm{W} / \mathrm{mm}^{2}\right)$ & 17 & 45 & 100 \\
\hline $\mathrm{EP}\left(\mathrm{mJ} / \mathrm{mm}^{2}\right)$ & 38 & 37 & 19 \\
\hline$\Delta \mathrm{T}_{\mathrm{f}}\left({ }^{\circ} \mathrm{C}\right)$ & 60 & 90 & 110 \\
\hline
\end{tabular}

As shown above we can estimate the FPI and EP, and $\Delta T_{f}$ of any stand/pass in the cold rolling process, and mimic these values in the tribometer. The rolling conditions considered in this report are those for stands 2 and 4 in a tandem sheet rolling mill, and stand 5 in a tinplate mill. See table 1 for some characteristic values. The tribometer consists of a ball loaded onto a disc. In order to achieve the required frictional conditions and flash temperatures, the ball and disc speeds as well as the load are carefully chosen. For the first set of tests the FPI and EP are satisfied simultaneously. In these tests, also the contact times, relevant in view of in-contact reaction times of ep/aw additives are similar to those in cold rolling. Furthermore, the 'recuperation times', relevant in view of the time available for the (work roll) surface to equilibrate again in its rolling emulsion environment before it enters the contact again, are also similar to those in cold rolling. For the second set of tests, the flash temperature was satisfied. In both sets of tests, sheet rolling stands 2 and 4, and tinplate rolling stand 5 are considered, so 6 tests are carried out in total.

In figure 10 a typical result is given of the 6 tests, referred to as 'FP 2', 'FP 4', 'FP 5' and 'Tf 2', 'Tf 4', 'Tf 5' for the tests mimicking frictional power and flash temperatures, respectively. It can be seen that the coefficient of friction decreases, which is due to a

* Contribuição técnica ao $51^{\circ}$ Seminário de Laminação - Processos e Produtos Laminados e Revestidos, 28 a 31 de outubro de 2014, Foz do Iguaçu, PR, Brasil. 


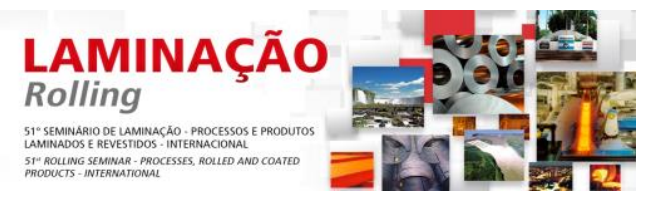

mild wear process, leading to some roughness decrease. It can also be concluded from the typical CoF values obtained in these tests, ranging between 0.06 and 0.09 that lubrication occurs in the mixed lubrication regime. Test results are generally given as the average CoF during the last quarter of the test, as shown by the columns in figure $10 \mathrm{~b}$. A further striking phenomenon in these (severe!) tests is that sometimes a failure occurs, accompanied by scuffing and high friction, after which the test is stopped. In such cases the CoF is not shown in the 'column' plot. Note that the 'Tf5' test is the most severe one. Crucially, in these tests, significant differences are found between various emulsions, depending on the composition of the product, but also on the emulsion concentration. Differences are found both in terms of the CoF values in the 6 tests as in the occurrence of failures.
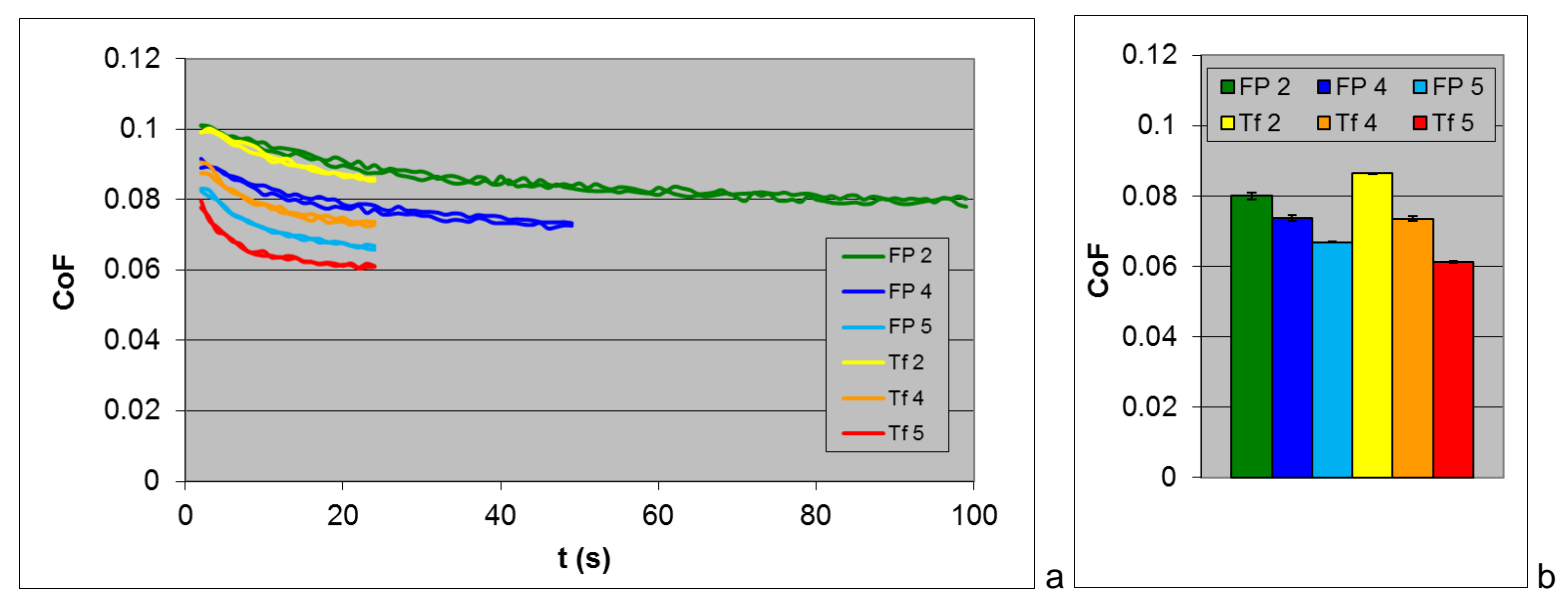

Figure 10. Representative results of the tests mimicking frictional power and flash temperatures in rolling (a) and the columns by way these results are represented in the remainder of the report (b).

The tests are interpreted as follows. The CoF values, as mentioned, are representative of the mixed lubrication regime. This means that the friction is governed by the CoF in the boundary and EHL regimes, as well as the film formation processes immediately in front of the contact. As was discussed earlier in this paper, these properties depend significantly on the lubricant (and emulsion) composition, and thus the test result is representative for the emulsion's rheological and tribological properties. Furthermore, the occurrence of a failure is a sign that the particular surface chemistry that prevents metallic contact (i.e. scuffing) is insufficient. This chemistry is of course the result of the reaction of the lubricant's ep/aw additives with the steel surfaces in aqueous environment. Any shortcomings in this respect are shown by a failure. Of course, a failure in the test does not imply a radically deficient performance in the field. It only indicates a shortcoming in lubrication on the microscopic scale under the chosen conditions.

\subsection{Examples}

In figures 11 to 14 some examples are given of the correlation of the newly developed emulsion tests mimicking frictional power intensity and flash temperatures with the performance in the field. The values of the CoF as well as the tendency for a failure in the test may correlate with field performance.

\footnotetext{
* Contribuição técnica ao $51^{\circ}$ Seminário de Laminação - Processos e Produtos Laminados e Revestidos, 28 a 31 de outubro de 2014, Foz do lguaçu, PR, Brasil.
} 

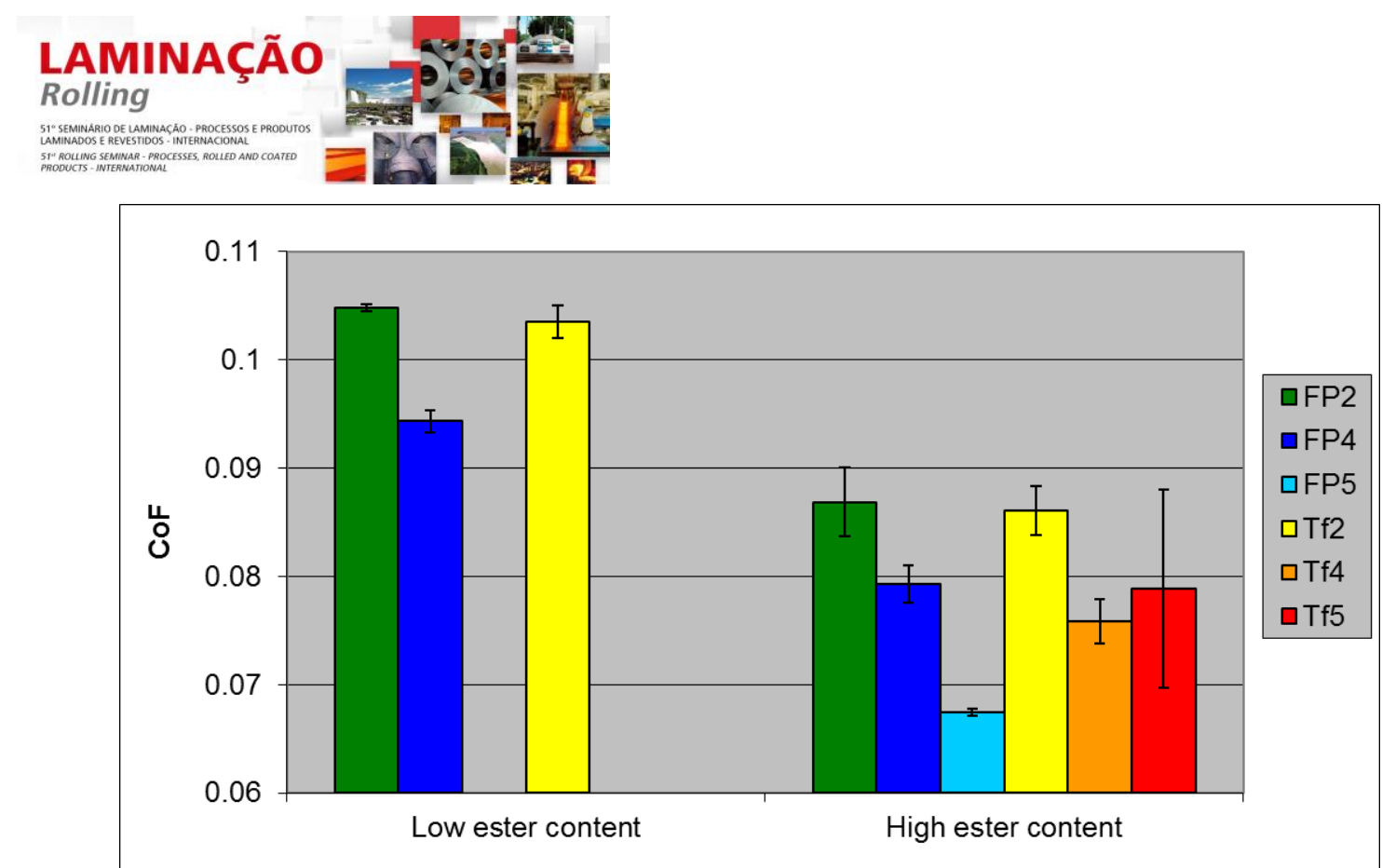

Figure 11. Lab results, example 1: CoF and tendency for failures is much lower for the emulsion with a high ester content. The rolling performance of this emulsion is also much better than for the other one.

In figure 11 can be seen the results for two different emulsions, one of a product with low ester content (and high mineral oil content) and one of a product with a high ester content. The latter passes all tests with relatively low CoF values, while the former fails in 3 tests. It is well known that ester-based products perform much better in the field, with lower roll forces and higher speeds attainable.

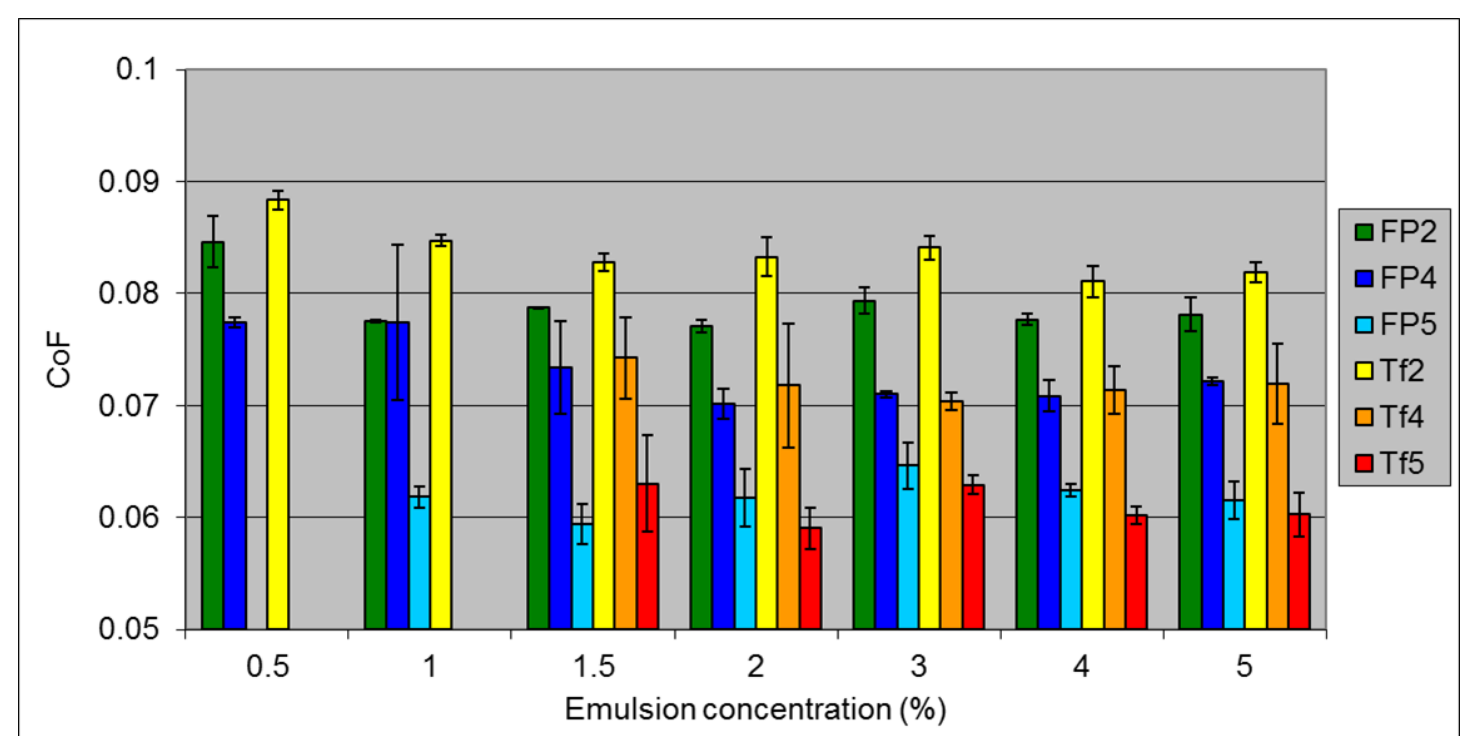

Figure 12. Lab results, example 2: Tendency for failures decreases with concentration. Also rolling performance improves with emulsion concentration.

In figure 12 are given the test results of an emulsion at various concentrations. It is commonly found that rolling performance improves with emulsion concentration, with the largest effect for the lower concentration range. This is clearly reflected in the test results, where increased emulsion concentration leads to lower CoF values, but especially less tendency for failures. The effect is most noticeable between 0.5 and $1.5 \%$. At higher concentrations no further improvement in test result is seen.

* Contribuição técnica ao $51^{\circ}$ Seminário de Laminação - Processos e Produtos Laminados e Revestidos, 28 a 31 de outubro de 2014, Foz do Iguaçu, PR, Brasil. 

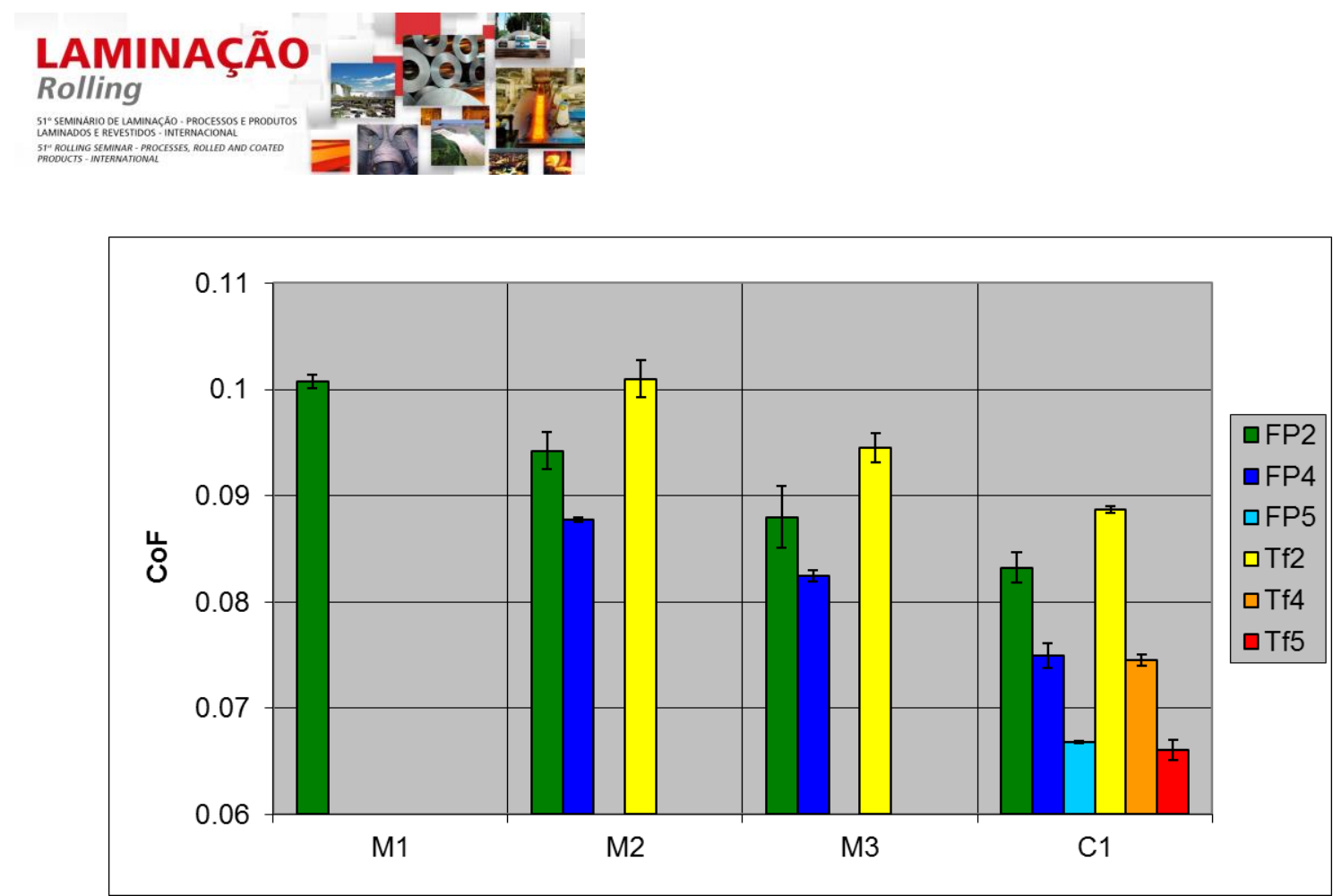

Figure 13. Lab results, example 3: CoF and tendency for failures decrease $M 1>M 2>M 3>C 1$. Achieved reductions in a pilot mill increased going from Emulsion M1 via M2 and M3 to C1.

In figure 13 are plotted the results of emulsions of three model products and one commercial product, which were also tested on a pilot mill. It can be seen that the CoF values decrease going from Emulsion M1 via M2 and M3 to $\mathrm{C} 1$, accompanied by a decreased tendency for a failure. On the pilot mill (not gauge controlled, i.e. constant roll force) the achieved reductions at a rolling speed of $300 \mathrm{~m} / \mathrm{min}$ increased from $26 \%$, via $31 \%$ and $35 \%$ to $42 \%$, respectively.

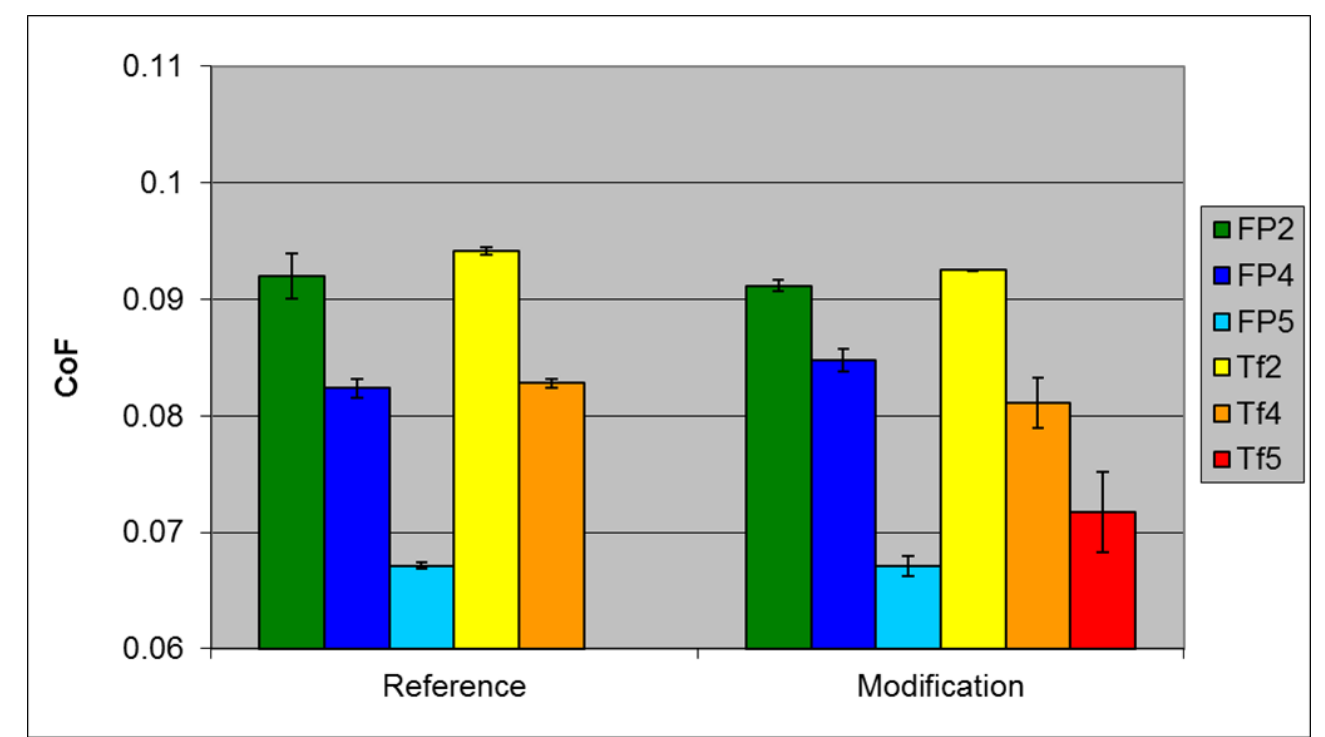

Figure 14. Lab results, example 4: The most severe test 'Tf 5' is passed for the Modification. This emulsion also shows lower roll forces in the field.

In figure 14 the results are plotted of a Reference emulsion that ran at a customer, but which was replaced by a Modification. It can be seen that in contrast to the Reference, the Modification passed the most severe test. In the field, using the Modification it was observed that roll forces on stand 1 were unchanged but depending on the steel type rolled, roll forces decreased between 6 and $13 \%$ on stand 2 , between 2 and $11 \%$ on stand 3 and between 0 and $11 \%$ on stand 4 .

* Contribuição técnica ao $51^{\circ}$ Seminário de Laminação - Processos e Produtos Laminados e Revestidos, 28 a 31 de outubro de 2014, Foz do Iguaçu, PR, Brasil. 


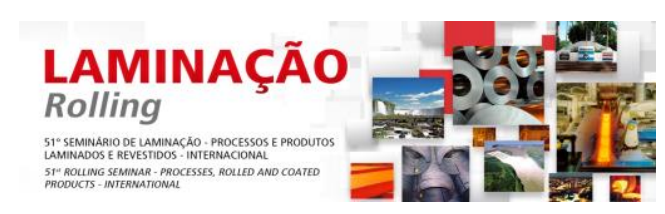

\section{CONCLUSION}

In this paper novel lubrication tests on emulsions are discussed. These not only involve film formation measurements and Stribeck curves, but also explore the boundary lubrication under severe conditions, where we see the influence of ep/aw additives. Carrying out these measurements on emulsions takes into account the various influences the presence of water has on fundamental physico-chemical processes in the entry zone and the roll bite. Due to the use of emulsions severe incontact conditions cannot be re-created by greatly increasing the temperature, but instead are obtained by mimicking the frictional power intensity and flash temperatures typically encountered in cold rolling. A good correspondence is found between these tests and (pilot) mill performance.

\section{REFERENCES}

1 Reynolds O. On the theory of lubrication and its application, Phil. Trans. R. Soc., 1886; 177: $157-234$.

2 Smeulders JBAF. Lubrication in the cold rolling process described by a 3-D Stribeck curve, Conference Proceedings, AISTech 2013 and the same paper in Iron and Steel Technology, February 2014: 37-45.

3 Kimura Y, Okada K. Film thickness at elastohydrodynamic conjunctions lubricated with oil in water emulsions, Proc. ImechE, 1987; 176: 85-90.

4 Bergmann M, Zeman K, Kainz A, Krimpelstätter K, Paesold D, Schellingerhout $P$, Smeulders $B$, Mixed lubrication model for cold rolling considering the inlet and deformation zones, Proceedings of the ASME 2012 International Manufacturing Science and Engineering Conference MSEC2012, June 4-8, 2012, Notre Dame, Indiana, USA.

5 Wilson WRD, Sakaguchi Y, Schmid SR., A dynamic concentration model for lubrication with oil in water emulsions, Wear, 1993; 161:207-212.

6 Barus $\mathrm{C}$. Isothermals, isopiestics and isometrics relative to viscosity, Am. J. of Science, 1893; 45: 87-96.

7 Roelands CJA., Correlation aspects of the viscosity-temperature relationship of lubricating oils, $\mathrm{PhD}$ thesis, Delft, 1966.

8 Ree $\mathrm{FH}$, Ree T, Eyring $\mathrm{H}$. Relaxation theory of transport problems in condensed systems, Ind. Eng. Chem., 1958; 50: 1036-1040.

9 Smeulders JBAF. Roll cooling and lubrication in cold rolling, in 'The Making, Shaping and Treating of Steel', Flat products volume, AIST, 2014, Chapter 13.2.

10 Plint MA, Alliston-Greiner AF. The energy pulse: A new wear criterion and its relevance to wear in gear teeth and automotive engine valve trains, Lub. Sci., April 1996, 8 (3), 233-251.

11 Blok H. The flash temperature concept, Wear, 1963; 6: 483-494.

* Contribuição técnica ao $51^{\circ}$ Seminário de Laminação - Processos e Produtos Laminados e Revestidos, 28 a 31 de outubro de 2014, Foz do Iguaçu, PR, Brasil. 